\title{
Wide Hysteresis NiTiNb Alloys
}

T.W. Duerig and K.N. Melton, Raychem Corp., Menlo Park, CA USA.

\section{Introduction}

In order to maintain the integrity of a shape memory coupling or fastener, it is essential that the installed parte remain austenitic throughout their service life. If they become martensitic, the recovery stresses will be reduced to the martensitic yield stress, or even worse, the two-way effect will cause the joint to physically separate. In the past, this has mandated the use of cryogenic alloys which remain austenitic at all normal service temperature, but must be expanded, stored, inventoried and assembled in liquid nitrogen to prevent premature recovery.

All solutions to this problem involve increasing the hysteresis of the alloys, or more precisely, separating $A_{a}$ from $M_{a}$ as far as possible, the reasoning being that $M_{\text {, }}$ controls the stress decay process mentioned above, while $A_{8}$ dictates the maximum storage temperature. Shipping temperatures can reach $45^{\circ} \mathrm{C}$ in extreme cases, so the unstressed $A_{0}$ of a successful wide hysteresis alloy must be at least that. How low the zero stress $M_{0}\left(M_{*}{ }^{\circ}\right)$ must be, however, is rather complex since fasteners and couplings are under stress and $M_{6}$ is a strong function of applied stress. In general one can calculate this from the following equation:

$$
M_{i} \cdot<T_{0} \cdot \sigma_{r}(d \sigma / d T)^{-1} \quad \text { Equ. } 1
$$

where $T_{0}$ is the lowest expected service temperature, do/dT is the stress rate of the alloy (typically $5 \mathrm{MPa} /{ }^{\circ} \mathrm{C}$ for $\mathrm{NiTi}$ ), and $\sigma_{r}$ is the minimum recovery stress needed to maintain product integrity. For most applications $M_{*}{ }^{\circ}$ must be below $-90^{\circ} \mathrm{C}$.

Although there are disordered shape memory alloys which show large hysteresis behaviors ( $\beta-T$ (1)) and iron based alloys (2), for example) long range order continues to be an important criteria for substantial shape memory strains and recovery stresses. $A_{0}$ is essentially the same as $M_{0}$ in CuZnAl and exceeds $\mathrm{M}_{\text {, by }}$ only $20^{\circ} \mathrm{C}$ in NiTi. In order to provide what has been dubbed "heat-to-8hrink" capabilities the hysteresis behaviors must be significantly expanded. Methods to expand the hysteresis of $\mathrm{Cu}-\mathrm{Zn}-\mathrm{Al}$ based alloys have been known for some time (3), but unfortunately this system has several attributes that make it imperfectly suited for coupling and fastener applications (poor 


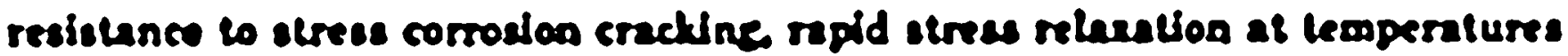
as low as $100^{\circ} \mathrm{C}$, and recorer atralns of oniy 3-52). Although tho MI.TI alloy

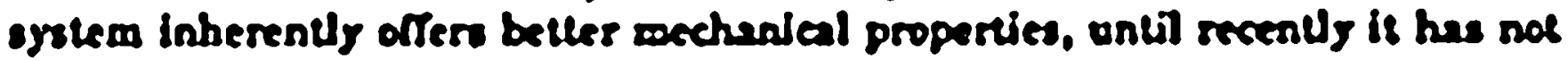
been possible wo achlowe tho dealred hyshercals characteriation. Tho Arat reparts of soch suceces werv. is lact, mported oaly 3 years aso (4-6) in a NiTI alloy containing 200000 ols $\mathrm{Nh}$. Sinco that lime, cerreral products bave bren brougbl into production using this important characteristle.

This paper reviewo the micronlneturo and properties of these NiTnib allon and

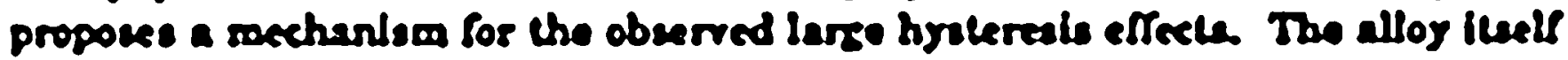

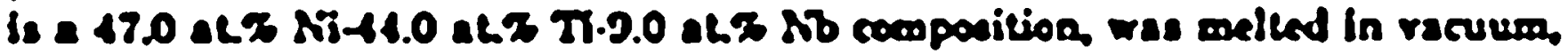
bol rolled and anoesied at $8500 \mathrm{C}$ in racuum prios to all leath.

\section{Silocatonclues}

The microsenectures of the Nithib allogs ars remertably diftereal froen binary Nitl alloge and other kerasy compositions (7). In the as-cast conditlon (Fisurs 1), ono observes a larse volumo fraction of second phase. forming as a eutectold with NITI. Ilol working breaks down the oulectoid alvucture, but the laree

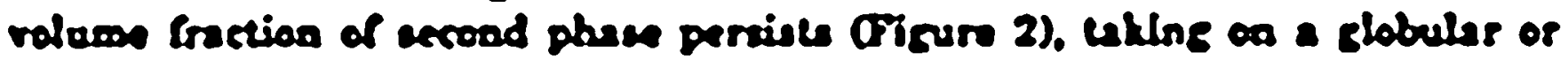
elliptical morpbolocy. Tho malrix phase has been shown (8) to bo escedtlally puro NiT, laking into solution only n small amount of Nb. Tho scond phase, on the ocher hand has inea ldealified to be neaply pure body ceaternd cuble Nib; if

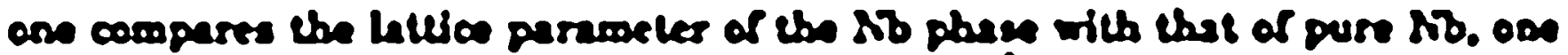
conclodes thas the phese enay in fact be pare (3.20al for the cecond phace verius $3.200 \mathrm{~h}$ for puro nlobium). Thus the microstructure is of a bimodal nature: a malrix of ordered Inlormolallic NiTn with the 112 structuro, and a dispercion of

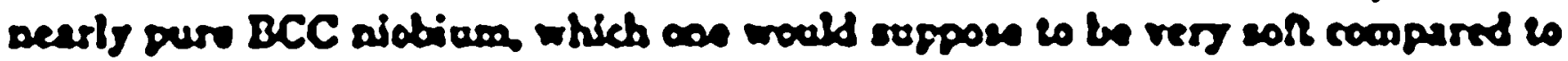
the auslenilie phace of the Sim.

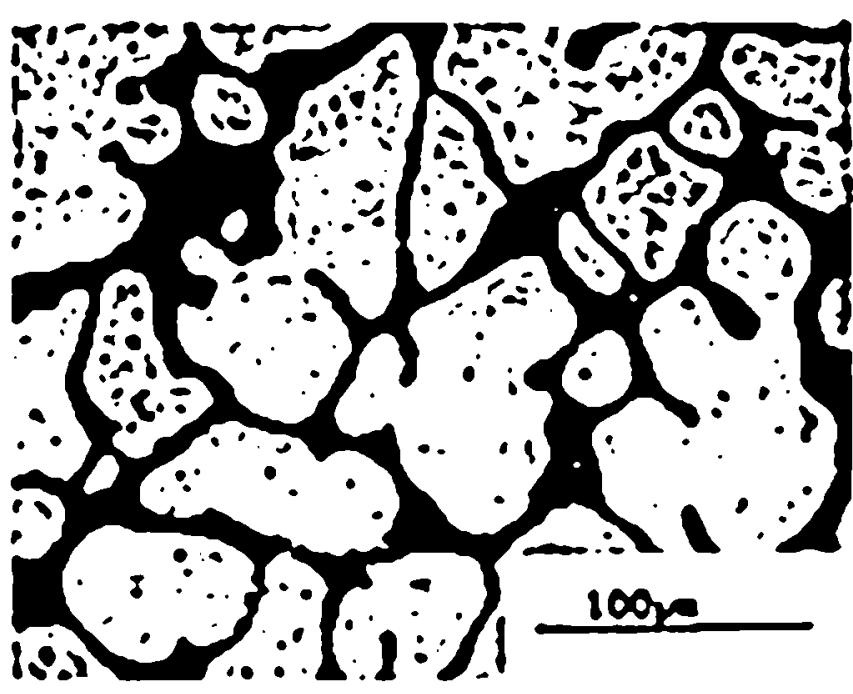

Fig li As-cast Nitisib structuro showine the lighe Nitr phase and dask eulectold.

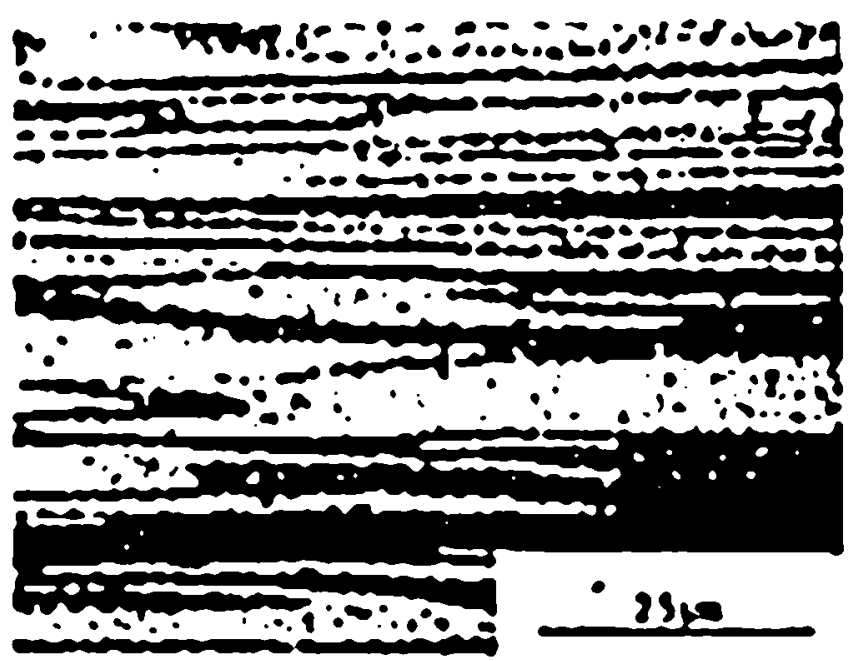

Tir. 2: Ilos rolled Airtisib with bands of cho eutocloid AL-Sist minture. 
Deformation Behavior

During deformation the phase mixture remains thermoolastic and exhibits shape memory. Deformation bolow $M_{\text {, }}$ is characterized by the variant reorientation plateau typical of NiTl binary alloys, with the exception that the plateau stress (otress neodod to move twin boundaries) is somewhat greater: 250 MaPa versus $150 \mathrm{MPa}$. The length of the platesu and the irreversible rield point appear to be largely unaffected by the dispersion. During heating, the deformed martensito will revert and recover ite original shape (Figure 3). The recoverable etrain in these alloys is as great as one would expect in binary alloys, bowever it is interesting to noto that recovery is imperfoct even after amall deformations. Binary alloge may recover perfectly afler deformations of over 7\%.

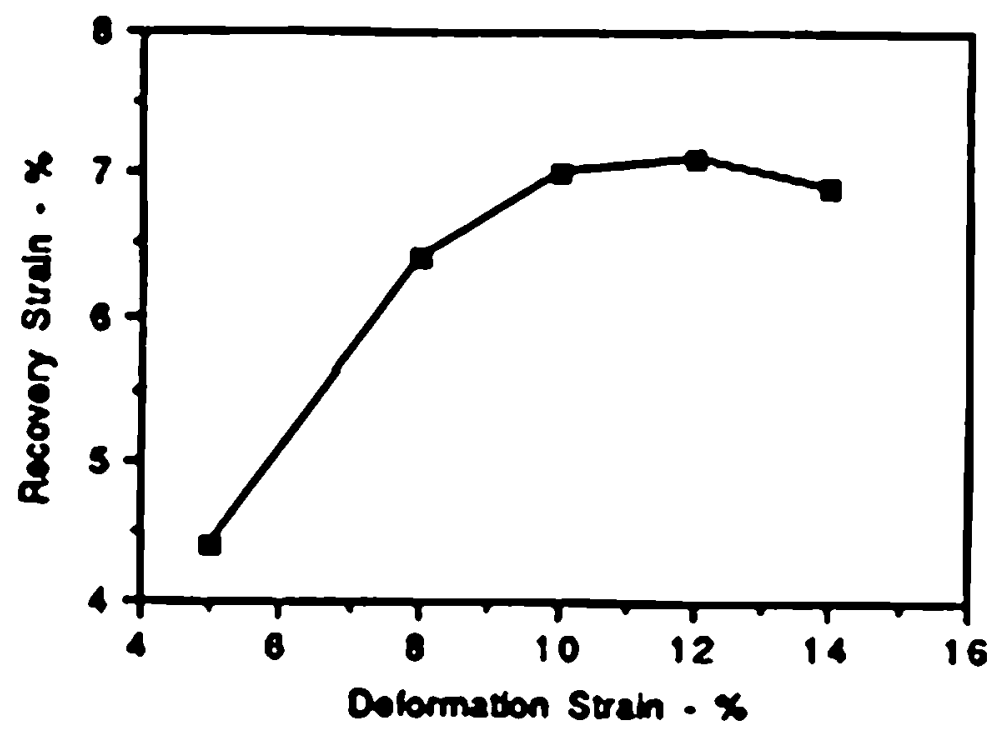

Fig. 3: Shape recovery strain (in tension) as a function of otal deformation strain.
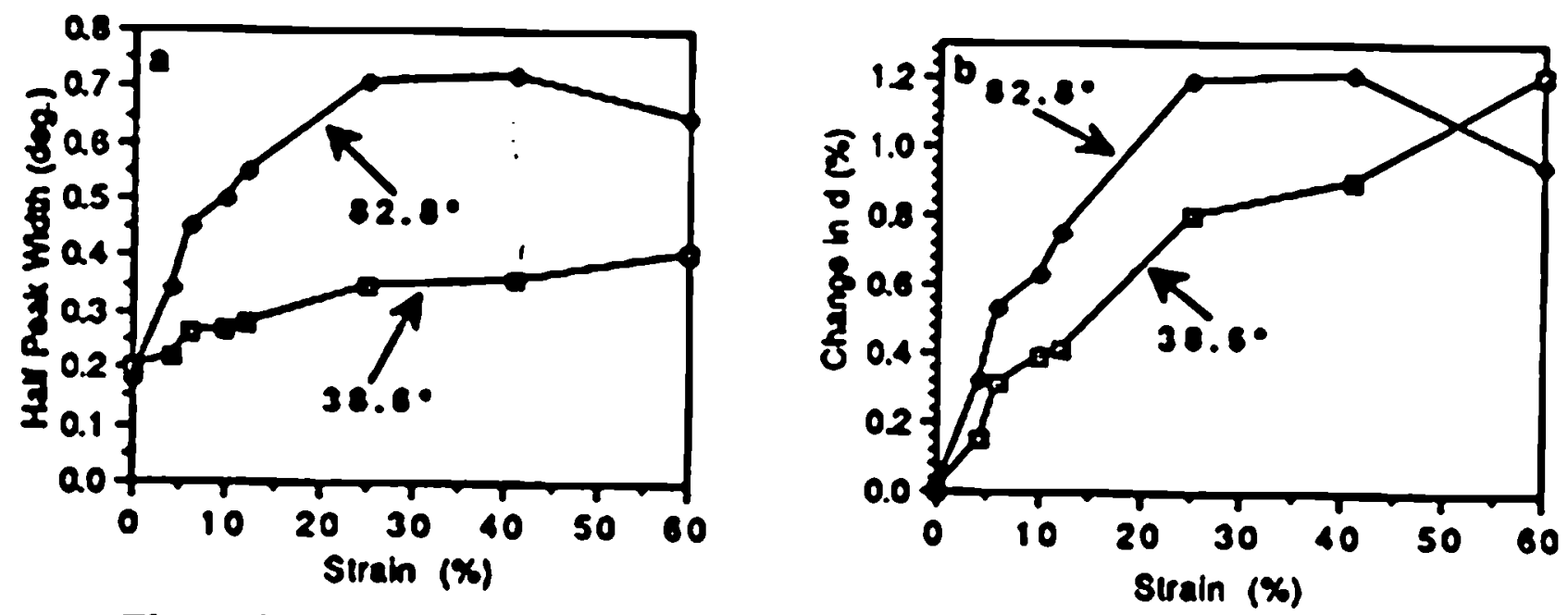

Fis 4: The rolationahip of macroscopic tensile deformation width $X$-ray peak width and change in lattice strain in the niobium phase. 
The deformation behavior of the niobium phase is more dificult to study. As said earlier, the rield stress of annealed niobium is very low (on the order of 200 MPa). Based on the heat troatment sequence described earlier, one would expect the niobium second phase 10 deform well bofore the matrix bocsine to alip, and in fact, to have roughly the samo Now stress as the twinning reorientation platcau of the matrix. In order to domonstrate this, tensilo specimens were deformed to various strains and then subjected to a particlo extraction process (5). The extractod particlos wero thon examined via X.ray difraction to look for line broadening (indicative of plastic doformation). This mothod quite clcarly demonstrated that the particlos in fact deform aner deformations as small as 4\% (Figure 4). Tho importance of this is that the colal deformation strain is apparently partitioned into irroversible and reveraible parts, the irreversiblo component being accommodated by the second phase. Further, from Figure 3 we can see that the irreversible deformation does not prevent shape recover from occursing.

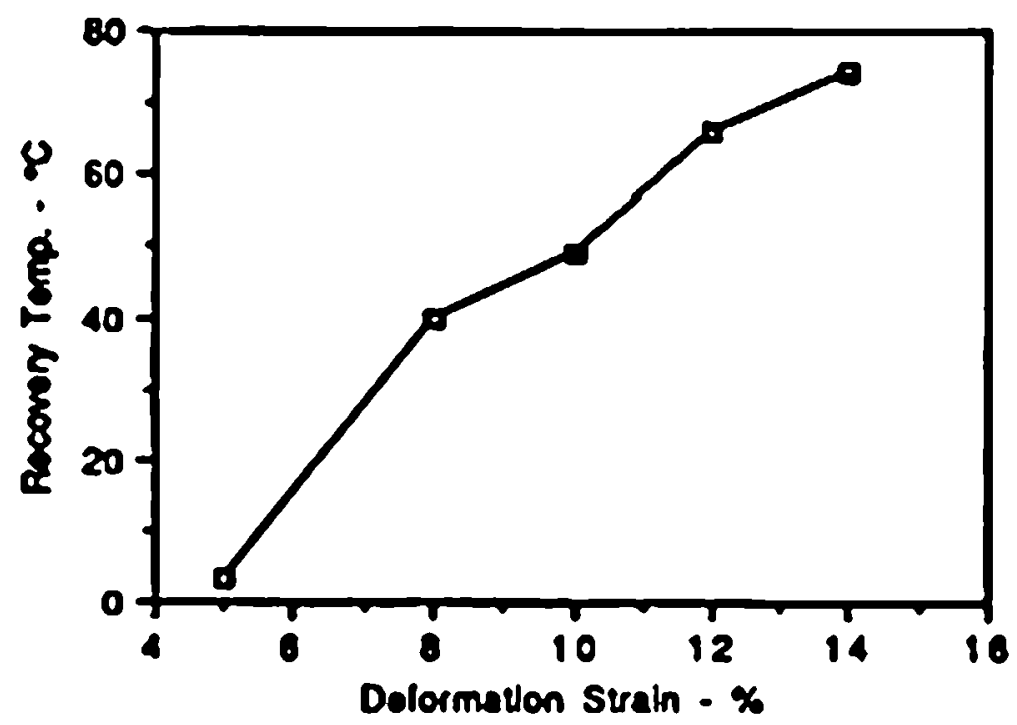

Fig. 5: The effect of deformation strain on A.:

Theromal bysteresia

The hysteresis of NiTiNb (as measured by electrical resistivity) was found to be comewhat greater than that of a binary NiTh alloy. Specifically, $M_{a}, M_{p} A_{a}$ and $A_{f}$ were found to be $\cdot 90, \cdot 175, \cdot 85$, and $-35^{\circ} \mathrm{C}$. If one defines the hysteresis as:

$$
\left(M_{0}+M_{1}\right) M_{2} \cdot\left(A_{0}+A_{1}\right) / 2 \quad \text { Equ } 2
$$

one finds a hysteresis of $72.6^{\circ} \mathrm{C}$ - nearly twice that of binary NiTi. What is more important, however, is the thormal hystercsis aflor doformation. The effect of deformation upon $A_{1}$ can oasily be measured by doforming in tension below $M_{\text {a }}$ 
and then monitoring strain while heating without load. The results of such an experiment are shown in Figure 5, and clearly demonstrate that $A_{a}$ is rather dramatically increased by relatively small strains. This displaced $A_{a}$ has been termed $A_{a}:$ It should be pointed out that similar effects have been observed in binary NiTi alloys, but the efrects are much smaller in magnitude(4).

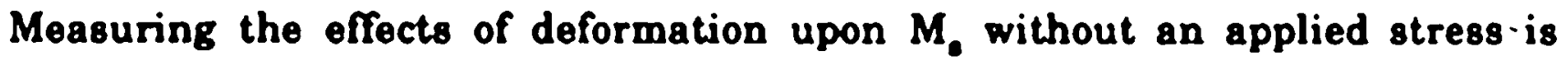
somewhat more difficult, but can still be done by monitoring the two-way effect during subsequent cooling. These experiments show that $M_{0}$ is not affected by the tensile deformation. Thus deformation is shown to increase hysteresis.

Finally, we can look at the second cycle $A_{\text {a }}$ meaning $A_{\text {f }}$ afer first heating above $A_{a}$ 'to recover the original shape, then cooling below $M_{\text {, }}$ and then measuring $A_{\varepsilon}$ during the next heating cycle. This second cycle $A_{a}$ is restored to the original, undeformed value. Thus the increase in $A_{a}$ to $A_{j}^{\prime}$ is temporary, affecting only the first heating. From Figure 5 it is evident that one can achieve $A_{\text {a }}$ values in excess of $50^{\circ} \mathrm{C}$, which provides a useful and stable storage condition.

\section{Mechanism of hysteresis expansion}

Relatively little is understood about what controls the hysteresis of NiTi-based alloys. Copper additions are well known to reduce hysteresis (10), but the exact mechanism of the effect is not understood. Alloys transforming to the R-phase prior to martensite formation and then transforming directly back to austenite upon heating exhibit slightly larger hystoresis loops then do materials not exhibiting R-phase behavior. This is easily understood on the basis of driving energy: the formation of R-phase from austenite reduces the driving force for martensite formation and thus suppresses $M_{\text {. }}$. Although there is some evidence that very long ageing times can slightly increase the hysteresis of Ni-rich alloys, generally speaking processing effects do not affect hysteresis. In this regard, the NiTiNb system would seem to be an exception. The second unique aspect of $\mathrm{NiTiNb}$ is that thermal hysteresis can be dramatically increased by relatively small deformations - deformations that do not, apparently, interfere with the memory effect.

The second of these features can be explained by considering the deformation characteristics of the model microstructure shown in Figure 6. Figure 6a shows the undeformed microstructure: a twinned martensite matrix with islands of soft second phase. Since we have already demonstrated that both phases deform, the deformed microstructure should look like that of Figure $6 \mathrm{~b}$ : the martensite is detwinned (showing a biased variant population) and the particles have been irreversibly deformed. Thus the total deformation is divided 
a

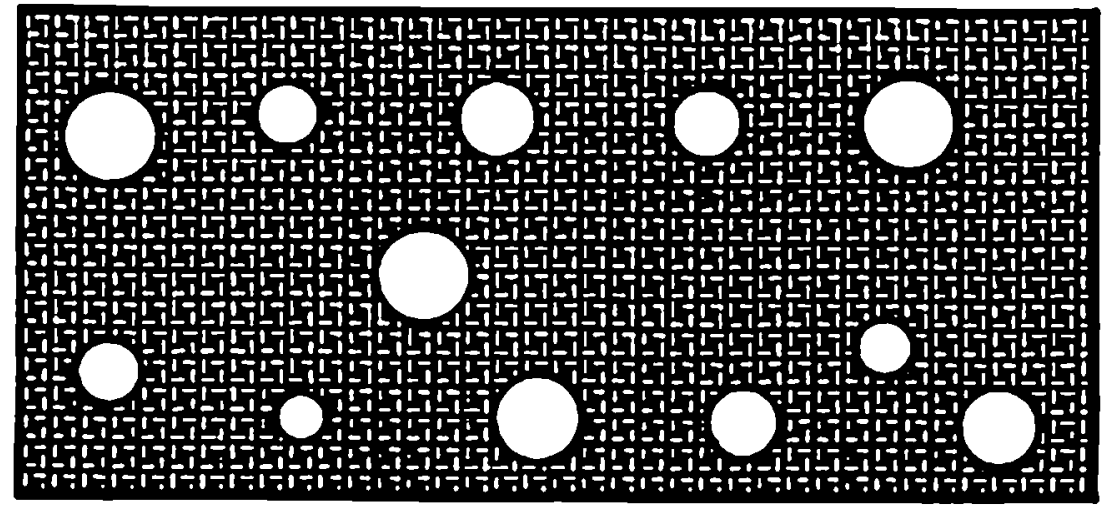

b

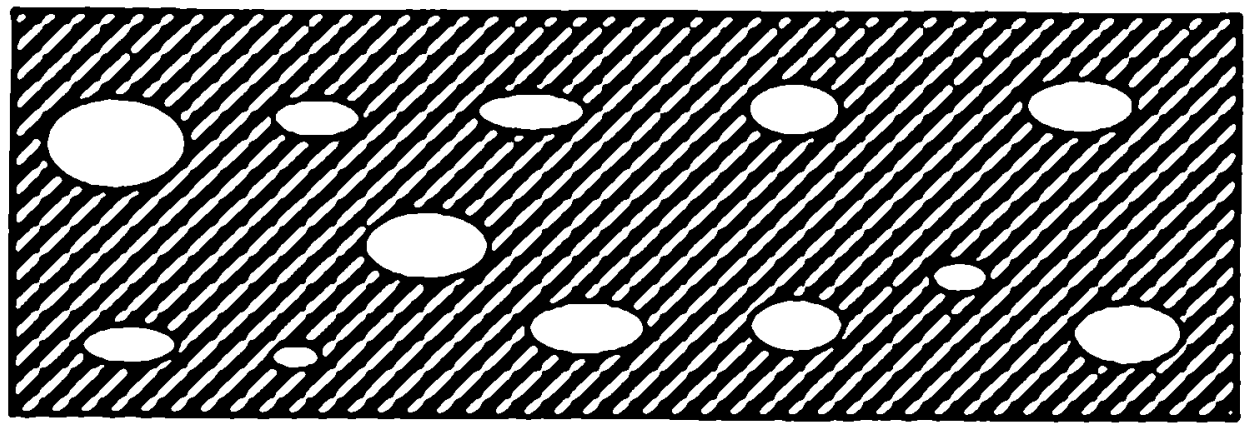

Figure 6: A schematic representation of how the NiTi-Nb phase mixture deforms: in (a), the undeformed structure is represented by spherical Nb particles in a randomly twinned martensitic NiTi matrix; after deformation (b), the particles are deformed and the martensitic twins develop a preferred variant. In order for the matrix to recover, the particles too must bo deformed back to their original shape (a), thus there is a stress resisting recovery and hysteresis is expanded.

into reversible and irreversible parts. During heating, the matrix tries to recover its original shape, but in doing 80 it must redeform the islands - thus the islands resist the shapo recovery process effectively providing an frictional stress. Since the recovery stress of the matrix is substantially greater than the How stress of the niobium particles, the shape memory process will take place despite the biasing stress from the islands, but $A_{a}$ should be increased by the frictional strcss, and the magnitude of the shin should be governed by the Clausius-Clapeyron behavior:

$$
\Delta A_{1}=\sigma_{f}^{N B}(d \sigma / d T)^{-1} \quad \text { Equ. } 3
$$

Where $\sigma_{f}{ }^{N B}$ is the flow stress of the niobium particles. In fact if one assumes 200 $\mathrm{MPa}$ for $\sigma_{f}{ }^{\mathrm{NB}}$ and $5 \mathrm{MPa} C$ for do/dT one expects an increase in $\mathrm{A}_{\text {o of }} 40^{\circ} \mathrm{C}$ : very near observed shifts. Once redeformed, the particles should again have no 


\section{References}

(1) C. Baker: Met. Sci. J. 5 (1971) 92.

(2) A. Nagasawa: J.Phys. Soc. Jap. 30 (1971) 1505.

(3) G.B. Brook, P.L. Brooks and R.F. Mes: U.S. Patent 4,036,669 (1977).

(4) L.C. Zhao, et al.: Transformation and Mechanical Behavior of a NiTiNb Shape Memory Alloy., Proceedings of the 1988 Meeting of the MRS in Tokyo.

(5) L.C. Zhao, et al.: The Study of Niobium Rich Precipitates in a Ni-Ti-Nb Shape Memory Alloy., submitted to Scripta. Met.

(6) K.N. Melton, J.A. Simpson and T.W. Duerig: ICOMAT-86, (1986) 1053.

(7) J.A. Simpson and D. Stoeckel: Pract. Met. 23 (1986) 357.

(8) J.A. Simpson, KN. Melton and T.W. Duerig: U.S. Patent 4,131,094 (1986).

(9) J.A. Simpson, K.N. Melton and T.W. Duerig: U.S. Patent 4,770,725 (1988).

(10) O. Mercier and K.N. Melton: Met. Trans. 10A (1979) 387. 